\title{
UNA FUNDACIÓN FAMILIAR DEL CARDENAL TAVERA: EL HOSPITAL DE SAN JUAN BAUTISTA EN TOLEDO*
}

\author{
POR \\ ANTONIO SÁNCHEZ GONZÁLEZ ${ }^{1}$ \\ Universidad de Huelva
}

\section{RESUMEN}

Uno de los mejores consejeros del emperador Carlos V, el cardenal Juan Pardo Tavera (1472-1545), fundó en las afueras de la ciudad de Toledo un imponente hospital bajo la advocación de San Juan Bautista, al que dejó como heredero universal de sus bienes. Además, el prelado quiso descansar eternamente en la iglesia de dicho hospital, con impresionante sepulcro en mármol obra de Berruguete, la misma iglesia en la que El Greco realizó sus últimos lienzos para cubrir los retablos del templo. También fue voluntad del cardenal Tavera dejar a su familia el gobierno del hospital, su principal obra, en condición de patronato laico, concretamente en la descendencia de su sobrino, el mariscal de Castilla Arias Pardo de Saavedra - los marqueses de Malagón, luego duques de Santisteban del Puerto y de Medinaceli-, en quienes quedó vinculado el patronazgo de este hospital toledano que funcionó como tal hasta el siglo XX y que hoy tiene otros usos culturales.

PALABRAS CLAVE: cardenal Tavera; hospital de San Juan Bautista (Toledo); marqueses de Malagón; fundación San Juan Bautista.

\section{A FAMILY FOUNDATION CREATED BY CARDINAL TAVERA: THE SAN JUAN BAUTISTA HOSPITAL IN TOLEDO}

\section{ABSTRACT}

Juan Pardo Tavera (1472-1545), one of the best advisers the for Emperor Carlos V, founded a large hospital in the outskirts of Toledo which was devoted to St John the Baptist and legally passed on to this religious order. This cardinal also made arrangements for his own burial in the hospital church and instructed Berruguete to design a marble sepulchre for him. The cited church also exhibited several very late paintings by El Greco which were displayed on the altarpiece. The cardinal also stipulated that the cited hospital should be part of a secular Board ruled by his family and, more particularly, by his nephew Arias Pardo de Saavedra, Marshal of Castile, and his sons (Marquises of Malagón, later Dukes of Santisteban del Puerto and Medinaceli). The cited Board was fully operative until the 20th century but nowadays the hospital is used for cultural purposes.

KEY WORDS: cardinal Tavera; San Juan Bautista Hospital (Toledo); Marquises of Malagón; San Juan Bautista Foundation

Cómo CitAR ESTE ARtículo / CitATion: Sánchez González, Antonio. 2021. «Una fundación familiar del cardenal Tavera: el hospital de San Juan Bautista en Toledo». Hispania Sacra LXXIII, 148: 403-417. https://doi.org/10.3989/hs.2021.031

\author{
Recibido/Received 06-02-2020 \\ Aceptado/Accepted $09-07-2020$
}

\section{INTRODUCCIÓN}

Al cobijo inicialmente de su tío Fray Diego de Deza (14431523), sobre todo durante la larga y final etapa del dominico

Este trabajo se encuadra en el marco del proyecto de I+D de Excelencia «La colección de Mapas, Planos y Dibujos del Archivo Ducal de Medinaceli: catalogación y estudio» (HAR2013-41500-P), del que el autor fue investigador principal, financiado en su día por el Ministerio de Economía y Competitividad.

1 antonio.sanchez@dhis2.uhu.es / ORCID iD: https://orcid.org/ 0000-0001-5025-455X como arzobispo hispalense, Juan Pardo Tavera (1472-1545) se labró una carrera eclesiástica que le llevó a ascender cotas hasta alcanzar la sede cardenalicia primada de España. Pero Tavera no solo prestó innumerables servicios a la Iglesia sino también a la Monarquía, hasta el punto de convertirse en estrecho colaborador, consejero personal y uno de los apoyos imprescindibles del emperador Carlos V. Tanto es así que, durante algún tiempo, ostentó temporalmente el gobierno de España como regente del Reino, en ausencia del emperador y por enfermedad de la reina. 
Como consecuencia de esos grandes servicios prestados acumuló un conjunto de bienes importantes, localizados principalmente en el reino de Sevilla y, en menor medida, también en Toledo. En Sevilla, además de las casas principales de la calle de Abades, junto a la catedral, poseyó un conjunto importante de propiedades rústicas en Utrera, Constantina, Villanueva del Río, Valencina del Alcor, Las Cabezas de San Juan y otros lugares principalmente del Aljarafe sevillano, además de diversas rentas en la propia ciudad hispalense. ${ }^{2}$

Con tales estipendios - más por los que recibió al servicio del trono que del altar-, benefició considerablemente a la descendencia de su único hermano, en particular al hijo varón, el mariscal de Castilla Arias Pardo de Saavedra, quien recibiría sucesivamente de su tío, el cardenal Tavera, hasta tres importantes donaciones por vía de mayorazgo (en 1517, 1524 y 1532), ${ }^{3}$ aparte de otros bienes posteriores igualmente vinculados por línea regular de primogenitura, sin dejar de atender, por ello, las dotes y otras necesidades de sus sobrinas, las hermanas de Arias Pardo.

Pero, por encima de todo, don Juan Pardo Tavera benefició a las personas que tenía a su servicio y, más aún, a la gente más humilde y necesitada de la sociedad, por cuanto designó por vía testamentaria como heredero universal de sus bienes al hospital que fundó y sostuvo extramuros de Toledo bajo la advocación de San Juan Bautista, conocido como de Afuera, situado frente a la puerta de la Bisagra y dedicado a «los tocados de diferentes enfermedades». ${ }^{4}$ El establecimiento combinó las innovaciones de la época en el campo sanitario con importantes novedades en el diseño arquitectónico. ${ }^{5} \mathrm{Y}$ en la imponente iglesia de dicho inmueble, además, quiso el cardenal descansar eternamente -como hoy reposa- en impresionante sepulcro en mármol de Berruguete.

Confió Tavera la administración y gobierno futuros de este hospital a un patronato familiar que inició el referido mariscal Arias Pardo y, en adelante, los descendientes de su linaje, titulados como marqueses de Malagón, por entronque además duques de Santisteban del Puerto, primero, y de Medinaceli después. Estos nobles han sido patronos gestores del hospital, desde entonces y durante su larga existencia como tal hasta después de la guerra civil española, además de custodios del impresionante edificio renacentista que le albergó, hoy con funciones culturales y educativas de museo, archivo histórico y colegio.

\section{JuAN PARdo TAVERA, DE VICARIO HISPALENSE A CARDENAL PRIMADO}

Siguiendo preferentemente a su biógrafo Pedro de Salazar y Mendoza, ${ }^{6}$ sabemos que Juan Pardo Tavera nació en Toro el 16 de mayo de 1472, en el seno de una familia de la nobleza castellanoleonesa, segundogénito del matrimonio formado por Arias Pardo y Guiomar Tavera.

2 Abreviaturas utilizadas: $A C S=A r c h i v o$ de la Catedral de Sevilla; $A C=$ Archivo de la Catedral de Toledo; $A D M=$ Archivo Ducal de Medinaceli; $A$ HPTO=Archivo Histórico Provincial de Toledo; AHPV=Archivo Histórico Provincial de Valladolid; $\mathrm{AHT}=$ Archivo Hospital Tavera; $\mathrm{RAH}=\mathrm{Real}$ Academia de la Historia.

ADM, Partido de Sevilla, leg. 1-1, 1-2 y 1-4, respectivamente.

Una aproximación a la terapéutica que se seguía en el hospital, a través del estudio de su farmacia, en Hermoso Armada 1988. Este aspecto queda aquí descartado.

5 Castán Lanaspa 1993, 365

6 Salazar y Mendoza 1603
Huérfano de padre a corta edad, fue criado por su madre, junto con su único hermano Diego, en la villa de Madrigal. En Salamanca recibió enseñanzas de latinidad y retórica por parte de su preceptor, el maestro Gumiel. Inmediatamente se graduó como bachiller de Cánones en la Universidad salmantina, en lo que sería el comienzo de una carrera eclesiástica fraguada al amparo de su tío materno, el dominico fray Diego de Deza, ${ }^{7}$ que por aquellos años era precisamente obispo de Salamanca. ${ }^{8}$ Este parentesco supuso la inserción progresiva de Juan Pardo en el grupo político 'fernandino' de la Corte, formado en torno al Rey Católico.

Su primer beneficio eclesiástico fue una capellanía en la parroquia de San Adrián de Salamanca, e inmediatamente fue nombrado racionero de la catedral de Zamora por parte por parte del propio obispo Deza. En 1500 obtuvo el bachiIlerato en Decretos, para alcanzar posteriormente los grados de licenciado y de doctor, llegando a ser Rector de la Universidad salmantina -elegido por unanimidad- entre 1504 y 1506 . En este último año Juan Pardo ocupó una plaza de oidor en el Consejo de la Inquisición.

Poco después fray Diego de Deza, siendo ya arzobispo de Sevilla, nombró a su sobrino canónigo de la catedral hispalense y, al año siguiente, lo elevó a la dignidad de chantre; además fue provisor, oficial y vicario general del arzobispado, donde ya dio buena cuenta de sus cualidades de gobierno, compostura y honestidad. Sirviendo en este cargo, el arzobispo sevillano requirió a su sobrino que despachara directamente en la Corte algunos asuntos importantes de la archidiócesis hispalense, lo que le permitió acudir a algunas audiencias con el rey Fernando, pudiendo el monarca comprobar las altas dotes del vicario sevillano. Por esta razón, el soberano le confió en 1513 la visita y reforma de la Real Chancillería de Valladolid, realizando Tavera una labor legisladora magistral. Como recompensa recibió al año siguiente la silla episcopal de la diócesis de Ciudad Rodrigo.

También confió en el obispo Tavera el cardenal Cisneros, a quien el regente le comunicaba los principales asuntos del Estado y le pedía su parecer sobre ellos. Probablemente su claro posicionamiento fernandino le hizo temer consecuencias negativas con la llegada de Carlos I a Castilla, pero pronto quedó también claro el solapamiento de intereses entre este grupo - del que Tavera formaba parte- y los servidores flamencos del nuevo monarca. De hecho, de inmediato el cardenal Adriano de Utrecht, consejero de Carlos I, a fines de 1521 le envía como embajador a Lisboa para concertar el doble matrimonio entre el propio emperador con la princesa Isabel de Portugal, hermana del nuevo rey luso Juan III, y el de éste con la infanta Catalina, hermana a su vez de Carlos 1. ${ }^{9}$ Dichos enlaces matrimoniales se celebrarían en los años inmediatos.

Por entonces, concretamente en 1522, se había producido la muerte del papa León X y, por influencia del emperador, subió al trono pontificio el cardenal Adriano de Utrecht con el nombre de Adriano VI. Este invitó a Juan Pardo Tavera

El dominico era primo hermano de Guiomar Tavera, la madre de Juan Pardo Tavera, como hijo de Inés Tavera y de Antonio de Deza. Los abuelos comunes de ambos fueron Juan Rodríguez Tavera `el Viejo' vecino y regidor de Toro, y Marina de Deza.

8 Una biografía del dominico en Cotarelo 1902. También es útil el estudio de Gámez Martín 2014.

9 Salazar y Mendoza 1603, 68-69. 
a que le siguiera a Roma para ocupar un alto cargo en la Santa Sede, pero el obispo de Ciudad Rodrigo rechazó este atractivo ofrecimiento excusándose en el gran respeto que le debía al emperador, con la seguridad de que también le necesitaba.

\section{FIGURA 1}

Retrato de Juan Tavera en la Sala Capitular de la Santa Iglesia Catedral de Toledo. Francisco de Comontes (1545)

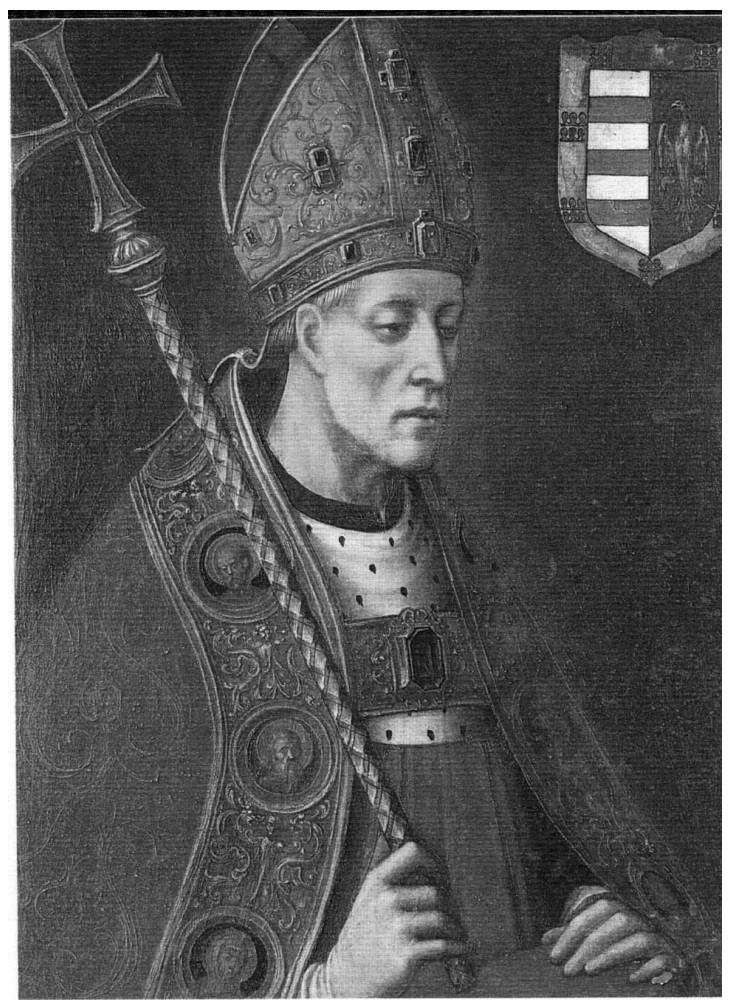

Tanto era así que, en septiembre de ese mismo año, Carlos I le nombraba presidente de la Real Chancillería de VaIladolid, estableciéndose desde entonces una colaboración tan estrecha entre ambos que no cesaron en el obispo Tavera los nombramientos y la ocupación de cargos eclesiásticos y políticos a instancias del propio emperador. Sopesado su paso a la sede episcopal de León, fue designado obispo de Osma a fines de 1523 y arzobispo de Santiago de Compostela en junio de $1524 .{ }^{10}$ Ese mismo año fue elegido presidente del Consejo Real (o Consejo de Castilla), cargo que ejerció durante tres lustros, y obtuvo el cardenalato con título de San Juan ante Portam Latinam en febrero de 1531, y el arzobispado primado de Toledo en abril de 1534.

El cargo de presidente del Consejo de Castilla obligó a Tavera a vivir en la Corte, muy alejado de sus obligaciones diocesanas, cosa que el prelado echó siempre en falta. Por este motivo hubo de asistir a las cortes celebradas en Toledo en 1525, a las de Madrid en 1528, Segovia en 1532, otras de Madrid en 1534, además de presidir las cortes de Valladolid en 1537 y las de Toledo del año siguiente. Una excepción fue

10 Sobre esta etapa compostelana ha tratado Olivera 1999. Véase, además, RAH, Colección Salazar y Castro, G-23, ff. 88-90 (n. 33445 del inventario) y ff. 90-92 (n.o 33446), ff. 185-187 (n.o 33513) y K-84, ff. 204-213 (n.ㅇ 42694). haber podido organizar en 1536 el sínodo o concilio provincial de Toledo. ${ }^{11}$

Durante todo ese tiempo había actuado también como consejero de la emperatriz en las regencias que ella desempeñó con ocasión de los continuos viajes del emperador por Europa y, consecuentemente, de sus dilatadas ausencias de España. A veces por enfermedad de doña Isabel de Valois, como en 1529, había tenido que actuar Tavera como gobernador de los reinos españoles, e incluso a la muerte de la emperatriz, acaecida diez años después, fue nombrado gobernador efectivo o regente del Reino durante dos años cuando el emperador se trasladó a sofocar la rebelión de los Países Bajos en $1539 .{ }^{12}$

El cardenal consigue entonces que, por fin, Carlos I le permita abandonar la presidencia del Consejo de Castilla pero, a cambio, además de gobernador le nombra Inquisidor General. En cualquier caso, pudo Tavera entonces dedicarse más ampliamente a su diócesis, que visitó en 1542 y 1543. Por esas fechas, el 15 de noviembre de ese último año, el arzobispo de Toledo ofició en Salamanca la ceremonia matrimonial del príncipe Felipe con la infanta María Manuela de Portugal. Y meses después, oficiaría en Valladolid las exequias de esta princesa, fallecida el 12 de julio de 1545 sin llegar a ser reina de España, cuatro días después del parto del infante Carlos. También el cardenal, como veremos, encontraría la muerte por entonces.

\section{BIENES PATRIMONIALES DEL PRELADO}

Juan Pardo Tavera no solo empezó a labrarse un status importante dentro de la Iglesia como prelado en su etapa hispalense inicial, junto a su tío fray Diego de Deza, sino que adquirió en el reino de Sevilla, mayoritariamente por vía de compraventa, una serie de bienes y rentas durante el primer cuarto del siglo XVI, ${ }^{13}$ que iban desde sus casas principales en la calle de Abades de la ciudad de la Giralda, precisamente muy cerca de ella, ${ }^{14}$ y otras moradas rústicas, a un conjunto de donadíos, heredades y cortijos en diversas poblaciones próximas a Sevilla, la mayor parte situadas en el Aljarafe.

Así, en término de Constantina poseía las tierras de la heredad de Majalimar, el donadío de las Santeras, otro donadío de tierras perteneciente al del Álamo y una haza de tierras llamada de Villaltilla. ${ }^{15}$ Por su parte, en término de Villanueva del Camino (o Villanueva del Río), poseía el obispo Tavera otro conjunto de tierras como el donadío de la Vega y Antona, haza del donadío de la Cruz frente al arroyo de Galapagar, cuadrejón de tierra del Guadaperos, haza de tierras en el donadío de Antona Pérez que llegaban hasta el

\footnotetext{
11 Martínez-Burgos 1997, 285-302.

12 Rumeu de Armas 2006, 166.

13 Más datos sobre este conjunto de bienes sevillanos de D. Juan Pardo Tavera en Sánchez González 2021, 235-237.

14 Estas casas principales de Sevilla las adquirió Tavera, por vía de compraventa, a los hijos del caballero veinticuatro del concejo hispalense Melchor Maldonado y, efectivamente, se hallaban situadas muy cerca de la catedral (véase ADM, Partido de Sevilla, leg. 1-2). También poseía el obispo otras casas principales en Villanueva del Camino, que habían sido adquiridas por el prelado en compraventa al matrimonio Juan Pérez de Cueva e Isabel Melgarejo, vecinos de Sevilla (véase ADM, Partido de Sevilla, leg. $1-1$ ).

15 ADM, Partido de Sevilla, leg. 1-1.
} 
barranco del Guadalquivir, donadío de tierras de la huerta de Calillos y otras dos hazas en el mismo donadío -una de ellas en la vega de las Anconillas-, otra haza de tierra conocida por la Dehesilla y otra que iba junto al camino de Cantillana por el arroyo Bermejo, la haza de Argamasilla y otras más del mismo término. ${ }^{16}$

Por otro lado, en término de Utrera, el prelado era propietario del donadío de Pardales, que lo adquirió en 1521 por compraventa a Mencía de Zúñiga por un importe de 1.125.000 maravedís. ${ }^{17}$ Posteriormente, lindero con Pardales, adquirió Juan Tavera otro donadío en 1523 a través de la venta de Juan de Valtierra y su mujer, con un costo de 14.000 maravedíes $^{18}$. $Y$ uotro pedaço de donadío y tierras de pan llevar», con lindes en los también donadíos de Zarracatinejos, la Goronda (¿hoy La Gironda?) y Casablanca (hoy término de Arahal). En ese mismo año, Juan Tavera también les compra a los propios Juan de Valtierra, María de Zúñiga y los hijos de ambos la mitad del dicho donadío de Zarracatinejos, en el mismo término de Utrera, por un total de 64.000 maravedís. ${ }^{19}$

Igualmente poseía el obispo Tavera en Valencina del Hoyo o del Alcor (hoy Valencina de la Concepción) una suerte de tierras de 17 aranzadas conocida como La Lampa, que había adquirido por compraventa de la familia Saavedra. ${ }^{20} Y$ también era propietario el obispo, en término de Las Cabezas de San Juan, de los donadíos de Torralba, que adquirió en enero de 1532 del conde de Miranda por un coste de algo más de dos cuentos de maravedís, ${ }^{21}$ y La Palmilla y Piñuela, que habían pertenecido a la casa de Medina Sidonia. ${ }^{22}$

Y en cuanto a rentas, poseyó don Juan Pardo Tavera en su etapa sevillana, entre otras, 17.000 maravedís anuales, de los cuales 14.000 eran en unos cañamares del término de Villanueva del Camino, por compraventa al matrimonio Juan Pérez de la Cueva e Isabel Melgarejo, y los restantes 3.000 sobre unas tierras y viñedos que el mismo Juan Pérez le vendió. ${ }^{23}$ También Juan Tavera había adquirido entre 1521-1522 un tributo perpetuo total de 5.700 maravedís, 3.000 de ellos por un molino de pan, con su batán, llamado el Palomar y situado en las proximidades del río Huéznar -afluente del Guadalquivir- que había adquirido el obispo de Francisco González de Merchante, otros 1.200 «que me vendió Miguel López y su hijo Francisco Rodríguez, vezinos del dicho lugar de Villanueva, sobre unas casas en el dicho lugar» y los restantes 1.500 maravedís sobre un molino llamado el Carretero, en la ribera del Galapagar, comprado al mismo González Merchante. ${ }^{24}$

Poseía también el obispo en la ciudad de Sevilla un juro de 200.000 maravedís anuales compuesto por diversas ren-

\footnotetext{
16 Ídem.

17 Ibídem, leg. 1-29 (escritura de compraventa del donadío dada en Sevilla el 12 de abril de 1521) y leg. 1-2.

18 Ibídem, leg. 1-31 (escritura de venta del donadío dada en Sevilla el 11 de agosto de 1523).

19 Ibídem, leg. 1-54 (escritura otorgada en Sevilla el 12 de agosto de 1523. Tavera suscribe la compraventa como obispo de Ciudad Rodrigo y presidente de la Chancillería de Valladolid). Más adelante, concretamente en 1546, su sobrino compraría la otra mitad del donadío de Zarracatinejos.

20 Ibídem, leg. 1-2, f. 6. Véase Franco Silva 2001, 244.

21 Ibídem, leg. 2-7 y 8.

22 Ibídem, leg. 1-4 (documento inserto).

23 Ibídem, leg. 1-2, f. 5

24 Ibídem, leg. 1-2, f. 5v.
}

tas: 40.000 maravedís en la renta de la buhonería, 20.000 en la de la zapatería, 40.000 en la del mercadillo de tocas y 100.000 maravedís en la de lienzos y sayales, ${ }^{25}$ aparte de otros 167.500 maravedís anuales de juro al quitar sobre el pescado salado y otras rentas. ${ }^{26}$

Fuera del reino de Sevilla también adquirió el cardenal diferentes bienes, como unas casas en Valladolid y diferentes propiedades en Toledo. ${ }^{27}$

Una buena parte de estos bienes fueron objeto de sendas escrituras de donación suscritas por parte de don Juan Pardo Tavera, que quedaron vinculados sucesivamente mediante la fórmula de mayorazgo regular, en la persona de su sobrino Arias Pardo de Saavedra (¿1509?-1561) —antes llamado Antón de Deza-, mariscal de Castilla en sucesión de su abuelo materno, justicia y alcalde mayor de Sevilla y veinticuatro del concejo de la ciudad, único hijo varón de su hermano mayor Diego de Deza y su esposa María de Saavedra. La primera escritura la otorgó Tavera en Sevilla el 8 de octubre de $1517,{ }^{28}$ siendo obispo de Ciudad Rodrigo y residente en la ciudad hispalense, aún en vida de su hermano, ${ }^{29}$ y afectó a los bienes en Constantina y parte de los de Villanueva del Río; la segunda fue dada en Valladolid el 16 de marzo de 1524, siendo obispo de Osma, y se trató de los bienes del término de Utrera, Valencina del Alcor y otra parte de los de Villanueva; ${ }^{30}$ y la tercera escritura fue suscrita en Medina del Campo el 1 de julio de 1532, siendo ya arzobispo de Santiago de Compostela, referida particularmente a los bienes del término de Las Cabezas de San Juan y algunas rentas en la ciudad de Sevilla. ${ }^{31}$

\section{Testamento, muerte y enterRAmiento del CARDENAL}

En 1540 Juan Tavera ya había dispuesto la edificación de un hospital general extramuros de la ciudad de Toledo. Y aunque entonces tenía asignado otro lugar de enterramiento, finalmente decidiría sepultarse en la iglesia del hospital que había decidido fundar.

En realidad, muchos años antes, siendo arzobispo de Santiago de Compostela, Tavera había solicitado para panteón familiar la capilla que bajo la advocación de San Pedro se situaba en el lado del evangelio de la cabecera de la catedral de Sevilla, obteniendo licencia del cabildo en enero de 1525 con condición de que se comprometiera a adornarla «... a su espensa de retablo y rexa de hierro y ornamentos... segund la decensia del culto diuino e de la dicha santa iglesia e del lugar donde está situada...».32 Posteriormente obtuvo otra licencia, en 1537, para realizar una renovación de

\footnotetext{
25 Ibídem, leg. 5-25.

26 Ibídem, leg. 3-52.

27 Parte de ellos se desprende de las rentas que cobraba su heredero universal a principios del siglo XVII (Salazar y Mendoza 1603, 285-286)

28 ADM, Partido de Sevilla, leg. 1-1.

29 Podría ya encontrarse enfermo Diego de Deza, pues había testado en Sevilla el pasado 5 de septiembre (ADM, ibídem, leg. 2-58) y falleció poco tiempo después dentro del mismo año de 1517.

30 ADM, ibídem, leg. 1-2.

31 Ibídem, leg. 1-4. En esta escritura el cardenal llama a Arias Pardo «nuestro sobrino, que se a criado en nuestra cassa e tenemos en lugar de hijo».

32 ACS, Secc. IX (Fondo Histórico General), leg. 16 expte. 9; y ADM, Partido de Sevilla, leg. 9 - 57 y 58. Véase Sánchez González 2016, 200.
} 
aquel recinto con el añadido de una sacristía, en previsible traza de Martín de Gaínza, ${ }^{33}$ proyecto que no llegó a materializarse porque para entonces el arzobispo Tavera ya tenía decidido su enterramiento en otro lugar. De hecho, ese mismo año de 1537 acometía obras Alonso de Covarrubias en la capilla de San Juan Bautista de la catedral de Toledo, por encargo del cardenal, con la intención de que sirviera de lugar de enterramiento, como así solicitó Tavera al cabildo dos años después. ${ }^{34}$ Pese a ello, a fines de 1540, teniendo ya fundado su hospital, pidió al propio cabildo un lugar en la capilla mayor de la catedral toledana, concediéndosele al lado de la epístola, bajo las gradas, justo enfrente de la sepultura del cardenal de España Pedro González de Mendoza, ${ }^{35}$ además de un suelo en el claustro para construir capilla. ${ }^{36} \mathrm{Y}$ ese iba a ser el lugar que tenía destinado don Juan Tavera para reposar eternamente hasta que, en 1544, debió de cambiar de idea ${ }^{37}$ por algún motivo que, por el momento, se nos escapa. El hecho es que, finalmente, el prelado decidió enterrarse - una vez que llegara el fin de sus días - en la iglesia del hospital toledano que, bajo la advocación de San Juan Bautista, se estaba construyendo a sus expensas.

Esa decisión final del prelado de enterrarse en el hospital toledano se convirtió en manifestación de última voluntad en el testamento dictado en Valladolid por Juan Tavera, sorprendido por la enfermedad cuando había acudido allí a celebrar las exequias de la princesa María Manuela de Portugal - primera esposa del futuro Felipe II- que había fallecido a mediados del mes de julio de 1545 tras el parto del infante Carlos, y estando ya el cardenal muy enfermo, los dos días anteriores a su muerte. ${ }^{38}$ Sin embargo, las obras del hospital toledano solo estaban iniciadas cuando se produjo el fallecimiento de Tavera en dicha ciudad, en la madrugada del 1 de agosto inmediato, lo que le había llevado a adoptar una medida provisional.

Primeramente queremos que, sy Dios Nuestro Señor se qysyere de me llevar desta enfermedad, my cuerpo sea sepultado en depósito en la yglesia mayor desta villa de Valladolid en la capilla mayor e para que de ally sea trasladado en la capilla questá traçada para se edificar en el hospital de Sant Joan que he hecho erigir y se edifica extramuros de la ciudad de Toledo, a donde queremos que sea trasladado en habiendo disposición segund el albedrio de mys testamentarios. ${ }^{39}$

33 ADM, Mapas y planos, no 491. Véase Sánchez González 2017, 110 y 416-417, plano comentado con A. Luque Teruel.

34 Salazar y Mendoza 1603, 312 y Díez del Corral 1987, 100

35 Salazar y Mendoza 1603, 313 y Fernández Collado 1999, 243.

36 Salazar y Mendoza 1603, 313-314. El propio biógrafo, al que han seguido otros autores, afirma que fue el deseo de Tavera de emular al cardenal Mendoza lo que le movió a querer enterrarse en el presbiterio de la catedral toledana; por eso su solicitud de que «el cabildo le celebrasse dos anniversarios con la solemnidad que se celebra el de el Cardenal don Pedro Gonçález de Mendoça...» (Salazar y Mendoza $1603,315)$

37 Así lo ve también Castán Lanaspa $(1993,367)$ asociando la idea al hecho de que fue en 1544 cuando se transformó el primitivo plan basilical de la iglesia del hospital que estaba erigiendo en Toledo «en otro centralizado, idóneo para su función funeraria».

38 ADM, Malagón, 11-52 y AHPV, Protocolos, leg. 98 (1545), ff. 435-581: Testamento del cardenal (Valladolid, 30 julio 1545). Véase Castán Lanaspa 1993, 365-378.

39 ADM, ibídem y AHPV, ibídem, f. 441.
La muerte del cardenal fue muy lamentada por Carlos V. El emperador siempre consideró a Juan Pardo Tavera la mejor cabeza de Castilla para los asuntos de gobierno, ponderando la importancia que había tenido para el gobierno y la administración tanto temporal como espiritual del Imperio español, también expresada en aquellas otras presuntas palabras que Fernández Duro atribuye a Carlos V al enterarse de su fallecimiento: "Se ha muerto un viejecito que me tenía sosegados los Reinos de España con su báculo», ${ }^{40}$ hasta el punto de que afirman algunos que el emperador lamentó más su pérdida que la de la propia reina, pues parece que dijo «mujeres hay muchas, pero Tavera solo hay uno ». ${ }^{41}$ Para Rumeu de Armas, como político fue «después de Cisneros, la figura de mayor significación de la centuria». ${ }^{42}$ También sintió mucho su muerte el príncipe Felipe porque «le respetaba y amaba como padre». ${ }^{43}$

Tras su muerte, los restos mortales del cardenal fueron depositados temporalmente, en efecto, en la capilla mayor de la antigua Colegiata de Santa María de la ciudad del Pisuerga, a cuyo funeral acudió toda la Corte

... los Grandes y Prelados, los Consejos todos, los Títulos y Caualleros, y personas de cuenta, lastimándose mucho de su muerte, porque generalmente estaua bien quisto, y era amado de todos los Estados. El mismo sentimiento se hizo en Toledo, y en todo el Arçobispado, en especial por los pobres, qve perdieron en él vn buen padre y amigo. ${ }^{44}$

\section{FIGURA 2}

Sepulcro de Juan Pardo Tavera en el crucero de la iglesia del hospital, obra de Alonso Berruguete (1559-1561)

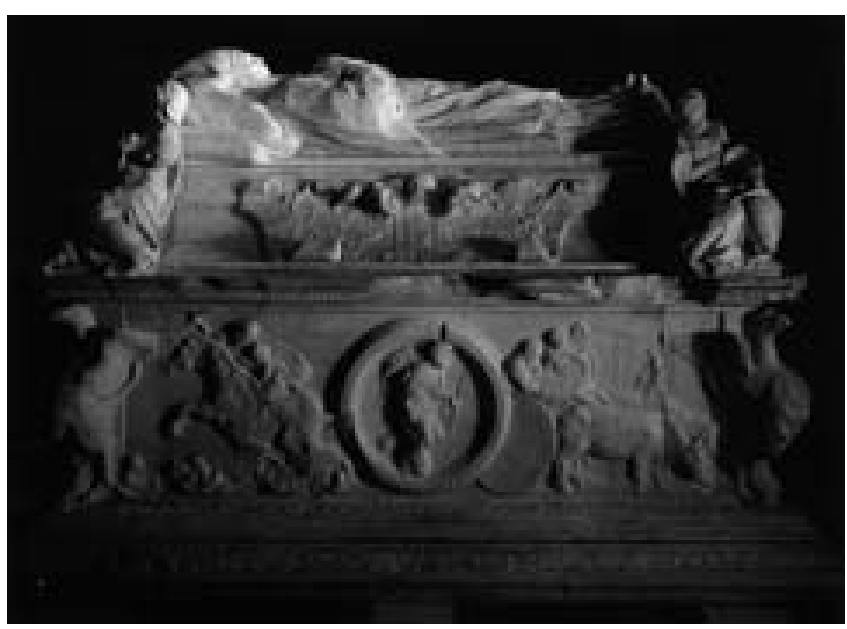

Fuente: Fotografía de Tomás Bartolomé.

Allí permaneció sepultado durante siete años ${ }^{45}$ hasta que, el 18 de octubre de 1552, en cumplimiento de su última voluntad, sus restos mortales serían trasladados so-

40 Fernández Duro 1891, 527; Paz y Remolar 1978, II: 126.

41 Marqués de Lozoya 1967, IV: 159.

42 Rumeu de Armas 2006, 163.

43 Salazar y Mendoza 1603, 352.

44 Ibídem, 354. En su testamento destinó el cardenal 12.000 ducados para socorrer a los más pobres del arzobispado de Toledo.

45 Con algún problema de los albaceas con el cabildo cuando pretendió bajar la altura de la tumba del cardenal (Castán Lanaspa 1993, 367). 
lemnemente a Toledo ${ }^{46}$ recibiendo sepultura dentro de los muros del hospital de San Juan Bautista, primero en la zona de la antigua capilla hospitalaria, con carácter provisional, y definitivamente, a partir de 1624, ya acabada completamente la fábrica, en el centro del crucero de la amplísima iglesia del hospital, donde se colocó el impresionante sepulcro que había labrado entre 1559 y 1561 Alonso Berruguete. Precisamente este sepulcro exento esculpido en mármol de Carrara había sido el último trabajo del insigne escultor castellano, quien falleció precisamente en el cuarto de debajo de la torre del Reloj de aquel magno edificio cuando acababa de finalizar el encargo del cardenal, para el que contó con la ayuda de su hijo Alonso Berruguete y Pereda.

Por la misma vía testamentaria, el cardenal Tavera dejaba a su hospital toledano como único y universal heredero de los bienes propios que poseía. ${ }^{47}$ De modo que, tras hacer algunas mandas a familiares y siervos, ${ }^{48}$ el documento se expresa así al respecto:

E cumplidas e pagadas las dichas deudas y descargos, hazemos e instituymos nuestro vniversal heredero, vsando de las facultades que para esto tenemos y conforme a ellas y también segund todo lo que por derecho e costunbre en este caso podemos disponer, al dicho nuestro hospital de Sant Joan para que suceda en todos nuestros bienes muebles y raizes, habidos e por haber, en qualquier manera que nos pertenezca o pertenecer puedan de los frutos y rentas del dicho nuestro arçobispado. ${ }^{49}$

Además, manda disponer de un servicio de capilla en el hospital, que encarga a sus testamentarios, ${ }^{50}$ no tanto para espiritualizar así su lugar de enterramiento si con la celebración del oficio divino cuanto para atender la cura de almas de los enfermos, estableciendo incluso los cargos y emolumentos de ocho presbíteros, un capellán, un sacristán y tres mozos de capilla.

E por quanto nos habemos eligido nuestra sepultura, segund dicho es, en la capilla del dicho hospital por qu'el culto diuino sea aumentado y el dicho hospital favorecido con alguna institución de capellanyas e capellanes que syrviesen en el ministerio del altar e en otros officios y cargos yguales neçessarios al dicho hospital por la orden y en forma y manera según las constituciones que ordenaren nuestros testamentarios, queremos y es nuestra voluntad que en la dicha capilla sirvan ocho presbíteros y vn capellán mayor de la mesma calidad y vn sacristán y tress moços de capilla,

$46 \quad$ Una descripción pormenorizada del traslado e itinerario seguido hasta Toledo por la comitiva en Salazar y Mendoza (1603, 376-379).

47 ADM, Malagón, 11-52 y AHPV, Protocolos, leg. 98 (1545).

48 Concretamente a su sobrina Guiomar Tavera, hermana de Arias Pardo, y a su esposo Juan de Ulloa Sarmiento (a quienes dona 14.000 ducados de oro); a los hijos de su primo Juan Ros Tavera; Ilamados Diego y Juan Tavera, que le servían desde 1523 (7.000 ducados) o a los hijos de su prima Inés Tavera, Magdalena (1.000 ducados de dote) y sus hermanos (3.000 ducados, a los tres en la misma proporción); e incluso a su agente en Roma, el licenciado Miguel Ortiz, además de su salario y «de lo que oviere gastado en nuestros negocios», entre otras muchas mandas (ADM, Idem).

49 ADM, Malagón, 11-52 y AHPV, Protocolos, leg. 98 (1545).

50 Fueron designados por el cardenal en su testamento, como albaceas, Juan de Zúñiga, comendador mayor de Castilla, el obispo de Badajoz Jerónimo Suárez, y sus sobrinos, el mariscal de Castilla Arias Pardo y Diego Tavera, arcediano de Calatrava y del Consejo de la Inquisición, electo obispo de Ávila y luego de Jaén. y que aya y lleue cada capellán en cada vn año quince mill maravedís e veynte hanegas de trigo, y el capellán mayor el dinero y trigo doblado que a vno de los otros dichos capellanes, y al sacristán diez mill maravedís e otras veynte hanegas de trigo, e a cada moço de capilla seis mill maravedís e doze hanegas de trigo, de las quales dichos capellán mayor, capellanes e moços de capilla guarden, cumplan e syrvan por el orden y en la forma e manera que fuere ordenada por los dichos nuestros testamentarios, a los quales para esto damos poder cumplido segund que es necesario...

Por otra parte, Tavera confiaba el patronato de esta fundación a su sobrino, el mariscal de Castilla, Arias Pardo de Saavedra, y luego perpetuamente a los sucesores de su casa y mayorazgo.

Y dexamos y nombramos por vnico patrón del dicho hospital, capilla, capellanes, officiales e ministros dél a nuestro muy caro e amado sobrino Arias Pardo de Saabedra, señor de la villa de Paracuellos, e al que después dél por tienpo fuere suçessor en su mayorazgo, e le damos derecho de nombrar los dichos capellanes oficiales e ministros que obieren de ser probeydos en el dicho hospital, los quales dichos capellanes quite e nonbre el arzobispo... 51

Pero también involucraba el propio Tavera a la Monarquía en el velar por la fundación de su hospital toledano, por cuanto añadía esta súplica en sus últimas voluntades:

E supplico humilldemente a su Magestad e al príncipe don Felipe nuestro señor tengan por bien de tomar entre sus reales cuydados e otras mayores ocupaçiones alguna parte del cuydado ques menester para esta obra pues va dedicada para el seruicio de Nuestro Señor, e la quieran mandar fauoreçer para que consiga entero efevto e perpetuydad, por el deseo que siempre he tenydo de seruir a su Magestad y a su Alteza. ${ }^{52}$

\section{LA EDIFICACIÓN DE UN HOSPITAL EN TOLEDO, VULGO DE} AFUERA

«...es de las más acertadas y excelentes fábricas que ay en Europa, y más conforme a las reglas y observaciones de la verdadera Architectura; [...] lo dizen los extranjeros que la vienen a ver, como a una de las maravillas de el Mundo» (Nicolás de Vergara, 1603).

El hospital de San Juan Bautista o de Afuera es, para Gómez Moreno, el primer edificio totalmente clásico de Castilla del Renacimiento ${ }^{53}$ y, para Fernando Marías, el gran monumento del Clasicismo toledano, compendio además de las diferentes tendencias arquitectónicas que se sucedieron durante tres cuartos de siglo..$^{54}$ De los diversos sitios que le propusieron para levantarlo, Tavera eligió en Toledo un lugar extramuros - si bien muy cercano a la muralla- situado frente a la nueva puerta de la Bisagra, junto al camino real de Madrid, que se conocía como plaza del Marchán. Se

51 ADM, Malagón, 11-52 y AHPV, Protocolos, leg. 98 (1545).

52 ADM, ídem. En el propio testamento el cardenal Tavera eximía al rey de 12.000 ducados, de los 24.000 que le había prestado «para ayuda a los gastos que continuamente tiene contra ynfieles».

53 Gómez Moreno 1983, 185.

54 Marías 2007, 49 y 61-79. Es la obra que preferentemente seguimos para la redacción de este apartado. 
trataba de un terreno elevado y atravesado por aires saludables, con cuestas por levante y poniente por las que se bajaba al barrio de las Covachuelas y a la Vega toledana.

Elegido dicho lugar para la fábrica del hospital, el cardenal envió a fines de 1540 a su criado Pedro Navarro, canónigo de la catedral, al concejo de la ciudad para solicitar el terreno. La cesión no solo fue inmediata, sino que el consistorio municipal en pleno visitó al prelado para agradecerle sus intenciones. ${ }^{55}$ Además, el 6 de enero de 1541 escribía el cardenal a seis agentes de la Corte para que diesen cuenta al emperador de los planes que tenía acerca del proyecto de construcción de un hospital en Toledo, lo que alabó Carlos $V$ en la carta que le dirigió desde Spira el 5 de febrero inmediato y le autorizaba a que llevara su proyecto adelante. ${ }^{56}$ También obtuvo bula facultativa de Paulo III, suscrita en Roma el 15 de marzo inmediato, en la que el papa facultaba al cardenal Tavera para nombrar administrador, capellán y demás ministros encargados de su gestión, así como para hacer las constituciones que habrían de regirlo. ${ }^{57}$

Así, el 28 de marzo se comenzaron a juntar los materiales necesarios para la obra de la fábrica, el 30 de julio de ese mismo año se dieron los primeros contratos de sillería, el 9 de septiembre se inició el allanamiento del solar concluyendo el 11 de marzo de $1542^{58}$ y se colocaba la primera piedra en presencia del arquitecto responsable de la ejecución del proyecto, el maestro mayor de la catedral toledana Alonso de Covarrubias. ${ }^{59}$

Ya existía un primer proyecto o traza inicial de lo que sería la construcción del hospital, que puede estar muy relacionada con el plano coetáneo existente, atribuido con toda lógica a Covarrubias, que presenta un edificio rectangular, con la fachada principal orientada al sur - mirando a la ciudad de Toledo-, organizado en torno a dos patios separados por una crujía intermedia en donde se situaban la caja de escalera y la capilla.

Dicha traza fue inmediatamente modificada por otra nueva durante el bienio 1541-1542 por el propio Alonso de Covarrubias, convirtiéndose en lo que sería el proyecto definitivo, lo que se explica por el hecho de que a don Juan Tavera debía rondarle la idea, si no lo tenía ya decidido, de enterrarse en el hospital, lo que coincide además con la llegada a Toledo del sacerdote jesuita y secretario del cardenal, Bartolomé Bustamante, a quien se le ha venido atribuyendo erróneamente la paternidad, más o menos total, de la obra. ${ }^{60}$ Parece claro que el jesuita, por encima de todo, actuó como veedor de la fábrica y administrador. También tuvo un papel de crítico - desde planteamientos arquitectónicos tradicionales- de las ideas y diseños de Covarrubias. Y como afirma Fernando Marías, a Bartolomé Bustamante le

\footnotetext{
55 Y eso que, por entonces, Toledo ya contaba con algunos hospitales dedicados a la asistencia de enfermos, además de numerosos establecimientos destinados a funciones de asilo (véase Zamorano 2002, 72-95)

56 AHT, Arca o Caja fuerte, doc. s/n.

57 AHT, Arca, doc. s/n. y ADM, Malagón, 11-51. Bula transcrita por Zamorano 1990, 130-135.

58 ACT, libro 626, ff. 1, 14, 26-27, 34, 42, 47, 52, 58-60, 70, 75-76, 90-91, 93 y 96.

59 Marías 2007,55 y 61-62.

60 Por parte, principalmente, de Rodríguez Gutiérrez de Ceballos (1967, 24-52) y otros, que le atribuían un decisivo papel en las trazas del edificio.
}

debió corresponder el trabajo de planificación utilitaria de la estructura general del edificio concebido por el arquitecto y su atención incidiría más en las necesidades prácticas de la fundación, siguiendo siempre las directrices del cardenal Tavera, y en controlar y limitar los gastos de la obra. ${ }^{61}$

FIGURA 3

Primitiva planta de Covarrubias (1540) para el hospital de San Juan Bautista, luego alterada

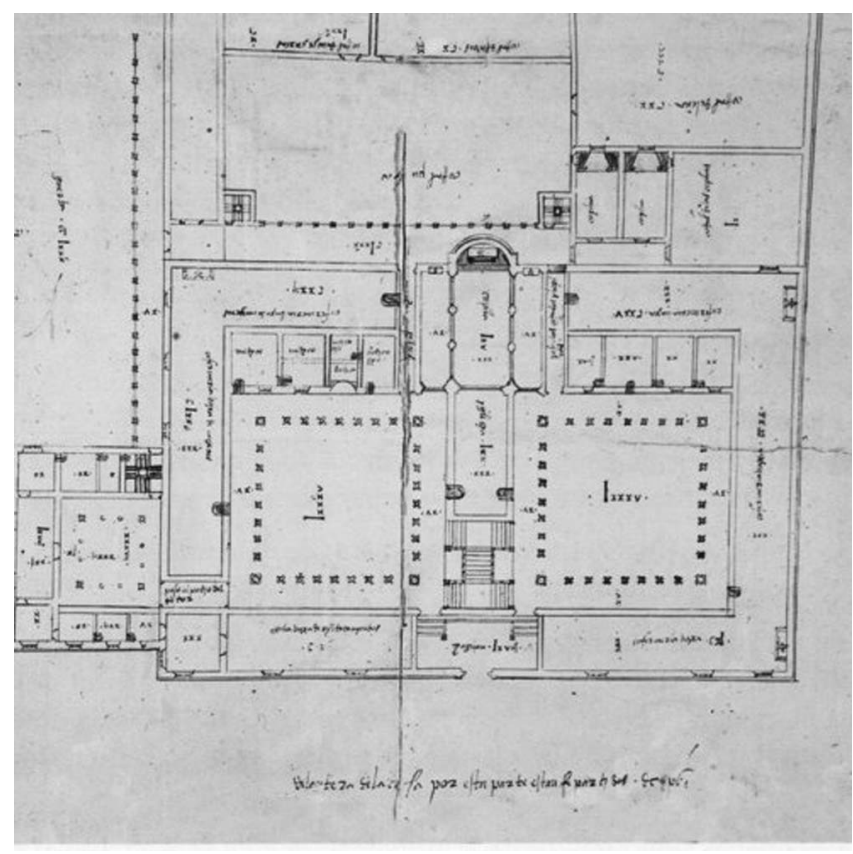

Fuente: Archivo del Hospital, arca, doc. s/n.

La disposición de la definitiva traza covarrubiesca se basa en un compromiso a partir de dos modelos distintos: por un lado, el tipo de hospital cruciforme materializado por su maestro Enrique Egas en Toledo, Santiago de Compostela y Granada; y, por otro, la reconstrucción quinientista de la domus romana amplissima descrita por Vitrubio y grabada por Fra Giovanni Giacondo da Verona en el tratado publicado en Roma el año 1486. De la primera fuente tomó Covarrubias la subdivisión de dos cuartos delanteros, y de la segunda la unificación de estos en una sola entidad espacial y la situación del templo al fondo. Con esta fusión de modelos, Covarrubias logró un equilibrio formal entre las dos zonas y funciones del edificio, la hospitalaria y la de iglesiapanteón. ${ }^{62}$

A Covarrubias se deben, así, diversas partes del conjunto que hoy podemos contemplar. En primer lugar, la fachada principal y la oriental (conocida como de San Lázaro), pero no sus portadas, con sus muros rústicos y sus ventanas de estilo serliano y sincopado ritmo alterno de raíz manierista italiana. En segundo lugar los patios, sobrios y desornamentados, ortodoxos en su superposición de órdenes (toscano y

61 Marías 2007, 10 y 103-107.

62 De esta manera podemos decir, respecto a la primera traza, que en el proyecto definitivo del hospital se cambia la situación de la escalera y de la iglesia y se deja diáfana la galería o intercolumnio existente entre los dos patios gemelos, lo que posibilitó un juego de espacio y perspectiva que era nuevo en España. 
jónico), modernos en el ámbito hispánico de su tiempo por su solución de esquinas y sus abovedamientos por aristas, y extraordinarios por su riqueza espacial, apoyada en la galería central que permite una multiplicación de las vistas complejas de arquerías y columnas en sentido oblicuo y, desde la entrada y zaguán de acceso, se convierte en una pictórica reconstrucción de una perspectiva monofocal que conduce mágicamente a la puerta de la iglesia. En tercer lugar, debemos a Covarrubias varios interesantes proyectos no realizados pero que demuestran el grado de italianización del arquitecto. Uno de ellos habría sido el de las torres de remate de la fachada principal del edificio, con sus curiosos pisos altos de forma cilíndrica coronados con cúpulas recubiertas de tejas de cerámica vidriada en dos colores; ${ }^{63}$ otro proyecto inaplicado, aún más importante, fue el del templo sepulcral, que se modificaría más adelante.

\section{FIGURA 4}

Reconstrucción de la traza inicial de Covarrubias para la fachada principal del hospital, por Jerónimo Potenciano, 1912



Fuente: ADM, plano n.․ 540.

Sin embargo, no quiso el destino que el cardenal viera culminada su obra pues, como sabemos, fallecía en Valladolid el 1 de agosto de 1545. No habían transcurrido ni cuatro años desde que el propio don Juan Tavera pusiera la primera piedra del edificio, por lo que para entonces solo había dado lugar a sacar los cimientos, hacer los sótanos y levantar algunos de los arcos del patio. Tampoco le dio tiempo al cardenal a preparar las constituciones por las que debería regirse el hospital, aspecto que dejó encargado a sus albaceas testamentarios.

Durante los años inmediatos que siguieron a la muerte del cardenal las obras del hospital continuaron bajo el control -delegado ya por su primer patrono Arias Pardo- de Bartolomé Bustamante y la ejecución de Alonso de Covarrubias. Sin embargo, a fines de 1550 el arquitecto abandonaba la fábrica y era sustituido por su hasta entonces aparejador, Hernán González de Lara. Solo un año después haría lo propio el sacerdote Bustamante, dejando al nuevo maestro mayor con las manos libres para poder actuar, si bien siguiendo siempre las indicaciones del patrono único de la fundación hospitalaria, el mariscal de Castilla. Por estas fechas los patios se encontraban ya prácticamente acabados, así como los cuartos de la delantera y los de levante, a excepción de sus portadas principales.

63 Marías 2007, 11 y 97-103.
La primera tarea del recién nombrado maestro mayor de la fábrica González de Lara consistió en una nueva traza para la capilla sepulcral del edificio, resultando una iglesia de una sola nave con planta de cruz latina y decoración clásica que, gracias a Alonso Berruguete, se convirtió de inmediato en modelo de yeso. De 1552 son, además, las trazas del arquitecto para los repartimientos de los llamados cuartos de San Lázaro y de las cocinas. También se ocupó por entonces de la distribución de la galería de la fachada principal del edificio, donde redujo el número de vanos y modificó en dos ocasiones la composición de las torres de las esquinas, previstas en el proyecto de Covarrubias, cambiando las torres macizas por otras más ligeras, con dos o tres vanos arqueados sobre pilares en cada cara a los que irían adosadas las columnas corintias que debían sostener el friso superior. ${ }^{64}$ Más adelante, en 1560, el arquitecto comenzó la iglesia, tras revisión de sus trazas por parte de Andrés de Vandelvira incluyendo este las tribunas altas de los patronos, de cuyo proyecto solo realizaría la cripta funeraria. Años después, en 1568, Hernán González proyectó las doce portaditas «amarillas» de los corredores del doble claustro, las cuales demuestran su dependencia con respecto a los modelos serlianos. También se ocupó el maestro mayor por aquellos años de levantar los cuartos más septentrionales del hospital, que se prolongaban por detrás de la iglesia.

A la muerte de Hernán González en 1575, Luisa de la Cerda - viuda de Arias Pardo, como curadora de su hijo Juan Pardo- encargaba la dirección de las obras al arquitecto Nicolás de Vergara 'el Mozo', discípulo de Juan de Herrera, cuya primera intervención en el edificio consistió en levantar las torres de la fachada principal, modificándolas respecto a las primitivas trazas, y erigir las torres de la fachada oriental para reforzar la estructura edificada y poder dotar así a la institución hospitalaria de algunos espacios, sin romper con ello el esquema planimétrico original. También por aquellos años se construyeron las casas de la otra acera del camino de Madrid, por el mismo sector oriental del edificio, para alojamiento de la servidumbre del hospital.

Entre 1581 y 1606 Vergara se ocupó además de la obra más importante del conjunto, la iglesia, introduciendo las primeras modificaciones, siempre en su alzado, respecto al proyecto de su antecesor Hernán González. Así, a lo largo de ese período el templo quedó prácticamente acabado, cerrado el cimborrio, levantadas sus pirámides, pavimentado el suelo y concluida su espléndida sacristía. Al mismo Vergara 'el Mozo' se le deben también las puertas de granito de los corredores bajos del patio y la principal del llamado cuarto de San Lázaro. El clasicismo reductivo de Vergara preside el diseño de la sacristía, la sobriedad más absoluta en el caso del diseño de las portadas, y la riqueza sobria y monumental en las trazas de la iglesia-panteón. En esta obra, además, el interés clasicista por la coherencia proporcional raya a su máxima altura, al mismo tiempo que introduce las mínimas licencias que otorgaban novedad a una traza realmente clásica. ${ }^{65}$

Pequeñas intervenciones de remate y decoración de la gran obra del templo prosiguieron a lo largo de los primeros años del siglo XVII, ya por parte de otra joven hija de doña Luisa de la Cerda, llamada Guiomar Pardo Tavera, pues

64 Ibídem, 107-108.

65 Ibídem, 109-110. 
aquella había fallecido en 1596. Tales fueron, por ejemplo, el arreglo y asentamiento de la portada de mármol importada de Génova que colocó, en 1608, Juan Bautista de Monegro como acceso a la iglesia en el corredor norte de los patios. También dirigió Monegro las obras de yesería de la iglesia y la sacristía. Por su parte, su sucesor, Toribio González de la Sierra, dio las trazas que remataban la obra de la capilla, las portadas interiores y la portada a la antecapilla, de estilo monegrino. ${ }^{66}$

Por estas fechas, además, se acometía la ejecución de los retablos del templo, encargando la joven patrona a El Greco en 1608 sus "esculturas, ensamblaje, dorado y estofado». ${ }^{67}$ Aunque el contrato suscrito entonces obligaba específicamente al cretense a que «amaestre la obra y no [la] encargue ningún otro", el artista solo pudo dejar las trazas del altar mayor y de dos laterales, para cada lado del crucero, sin poder realizarlos materialmente al sobrevenirle la muerte en Toledo el 7 de abril de 1614. Sí había hecho previamente, en 1598, la custodia o tabernáculo del altar mayor, a la que pertenece su famosa figurilla de Cristo Resucitado que lo coronaba (única escultura conocida y probada de El Greco). Por esta razón la propia patrona del hospital encomienda en 1619 la ejecución de estos retablos al hijo del pintor cretense, Jorge Manuel Theotocópuli, quien debía seguir las trazas dadas por su padre. Además, las esculturas del retablo mayor fueron encargadas por esos años a Giraldo de Merlo, con excepción del santo titular San Juan Bautista, que realizó el flamenco Antonio Cuello, y del Crucificado que lo corona, cuya atribución a Berruguete parece estar descartada. ${ }^{68}$

El mismo año de 1622, en que fallece sin descendencia Guiomar Pardo, el hospital iniciaba un pleito con Jorge Manuel Theotocópuli debido, en gran parte, a que se deseaba amoldar la estructura plana del retablo mayor al ábside circular del templo, transformándolo en ochavado, lo que vino a suponer una modificación del primitivo retablo trazado por El Greco. ${ }^{69}$ En cambio, no debieron tener grandes diferencias respecto a lo inicialmente proyectado por el cretense, los retablos laterales del crucero, presididos respectivamente por dos grandes lienzos del insigne pintor: el de la Anunciación (que fue robado en el siglo XIX), para el lado del evangelio, y el del Bautismo de Cristo (última obra de El Greco), para el de la epístola, aunque este último estuvo inicialmente proyectado para ser colocado en el retablo mayor.

La impresionante iglesia del hospital fue consagrada solemnemente en 1624, ya con la tumba del fundador en el crucero, con lo que el magno edificio puede considerarse entonces ultimado en lo que sería su definitiva estructura. En adelante solo quedaron por hacer algunas obras puntuales.

\section{UN PATRONATO LAICO FAMILIAR}

Resulta sintomático que el influyente cardenal toledano no dejase esta magna obra bajo custodia de la Iglesia ni del

\section{Ibídem, 111.}

67 AHT, Arca, doc. s/n. y AHPTO, 30630, f. 804r-v: Contrato para la ejecución de los retablos del hospital de San Juan Bautista (1608); condiciones de la obra (ff. 805r-807v; obligación contraída por Jorge Manuel Theotocópuli de terminar la obra si su padre no llegase a hacerlo (f. 808r).

68 Véase Mann 1984.

69 AHT, Arca, doc. s/n. propio Estado, sino como fundación laica confiada a su familia por vía de patronato de sangre.

\section{Primeros patronos: los Pardo-Tavera}

El primer patrono de la fundación San Juan Bautista fue el sobrino varón del cardenal fundador, primogénito del matrimonio formado por su hermano mayor Diego Pardo de Deza y su esposa María Arias de Saavedra, ésta a su vez hija del mariscal de Castilla Gonzalo Saavedra. Se trataba del referido Arias Pardo Tavera (¿1509? - 1561), antes Ilamado Antón de Deza, que sucedió primero en el mayorazgo paterno como mariscal de Castilla y alcalde mayor de la ciudad de Sevilla. Además, había sido favorecido durante su vida con varios legados de su tío, el obispo Tavera, concretamente por el triple mayorazgo que le instituyó sucesivamente, primero por escritura otorgada en Sevilla el 8 de octubre de $1517,{ }^{70}$ luego en Valladolid el 17 de marzo de 1524, con ampliación patrimonial ${ }^{71} y$, por último, en Medina del Campo el 1 de julio de 1532, aumentado con otros bienes, ${ }^{72}$ todos en el reino de Sevilla. Tras la muerte del cardenal, como vimos, por las vías testamentarias del prelado sería designado además Arias Pardo, en 1545, patrono único del hospital San Juan Bautista.

Tales posesiones fueron las que le permitieron al mariscal obtener una serie de señoríos castellanos - desprendiéndose para su adquisición de parte de los bienes que poseía en tierras sevillanas-, como fue la compra a la Corona, primero de la extinta encomienda santiaguista desmembrada de Paracuellos de Jarama en 1542, por un coste de 42.024.579 maravedís $^{73}$ - de los que su tío le donó aproximadamente la mitad,$-{ }^{74}$ y seis años después, ya muerto el cardenal, la extinta encomienda calatrava de Malagón, el 14 de enero de 1548, por importe de 55.696.638 maravedís, con sus lugares anexos (Porzuna y Fuente el Fresno). ${ }^{75}$

Para entonces el mariscal de Castilla estaba casado con una hija de los segundos duques de Medinaceli, la referida doña Luisa de la Cerda, por lo que recibió también el notable prestigio que suponía enlazar con la casa nobiliaria que ostentaba el primer título de Castilla y una de las más poderosas del momento. ${ }^{76}$

El matrimonio tuvo cinco hijos y, sin embargo, la herencia se haría dificultosa en el futuro por la falta de posteridad de los descendientes. Así, cuando Arias Pardo falleció en Toledo, el 13 de enero de 1561, le sucedió efímeramente en el mayorazgo de la casa de Malagón su primogénito, llamado -en recuerdo del cardenal- Juan Pardo Tavera (15501571), titulándose segundo señor de Malagón, Paracuellos

\footnotetext{
70 ADM, Partido de Sevilla, leg. 1-1.

71 Ibídem, leg. 1-2.

72 Ibídem, leg. 1-4.

73 ADM, Paracuellos, leg. 2-2 (antes ADM, Medinaceli, leg. 181-

74 Véase ADM, Malagón, leg. 6-12, documento extractado por Campo Real 1997, 740-746.

75 ADM, Malagón, 1-21. Véase Campo Real 2000.

76 Luisa de la Cerda era hija legítima de Juan de la Cerda (14851544), II duque de Medinaceli, II conde de El Puerto de Santa María y señor de Deza, Cihuela, Enciso, Cogolludo, Huelva y otros dominios, y de su segunda esposa María de Silva y Toledo (1494-1544), hija de los condes de Cifuentes. De este segundo matrimonio del duque nacieron cuatro hijos más.
} 2). 
y Fernán Caballero, además de mariscal de Castilla. A él podemos considerarlo también segundo patrono del hospital San Juan Bautista, si bien es cierto - como pudimos comprobar - que quien realmente se ocupó de la gestión fue su madre, doña Luisa de la Cerda, como curadora de él y de sus hermanos.

Fue aquella una etapa muy interesante para el desarrollo de esta fundación. Ella sabía la importancia de reglamentar, para la posteridad, la gestión y los servicios de la institución hospitalaria pues, hasta entonces, se había venido funcionando con unas normas faltas de aprobación por parte de la autoridad competente ya que los albaceas del cardenal Tavera - incluido su marido - no habían cumplido con ese compromiso. De ahí que, solicitados los oportunos permisos ante la Santa Sede, el papa Pío V por bula expedida en Roma el 5 de junio de 1567, ${ }^{77}$ además de autorizar la conclusión de la edificación del edificio, también facultaba al joven Juan Pardo Tavera, en su condición de patrono único de la fundación, para nombrar a cuatro letrados (dos teólogos y dos juristas) que debían encargarse de elaborar las constituciones del hospital. El joven patrono delegó ese cometido en 1569 en el canónigo de la catedral toledana Diego Guzmán de Silva, para que designara a las personas más idóneas que debían redactar los estatutos. A tal efecto, los jueces apostólicos elegidos fueron los licenciados Pedro Velarde (inquisidor apostólico de Toledo) y Pedro Alonso de Valdivieso (presidente del Consejo de la Gobernación de dicho arzobispado y canónigo catedralicio), y los doctores fueron Alonso Velázquez (también canónigo toledano) y el franciscano fray Miguel de Medina, quedando las constituciones otorgadas el 31 de mayo de ese mismo año. Estas constituciones fueron presentadas por la propia Luisa de la Cerda, en nombre de su hijo, el 10 de junio inmediato ante el gobernador del arzobispado de Toledo Gómez Tello Girón, recibiendo la confirmación y aprobación de su Consejo el 24 de diciembre de $1569 .^{78}$

Poco después, el 22 de octubre de 1571, con solo 21 años de edad, moría el joven Juan Pardo Tavera, siendo aún soltero, y le sucedía tanto en el mayorazgo de la casa como en el patronato de la fundación San Juan Bautista su hermana Guiomar Pardo Tavera (¿1552? -1622), también entonces en edad juvenil y bajo custodia de su madre, la propia Luisa de la Cerda. ${ }^{79}$

En esta fase el papa Gregorio XIII concedía bula a la joven patrona facultándola en 1575 para hacer nuevas constituciones y reconociendo el derecho de los patronos a añadir o remover oficios en el hospital..$^{80} \mathrm{El}$ año antes la señora de Malagón, Guiomar Pardo, había contraído nupcias con Juan

77 ADM, Malagón, 11-55.

78 ADM, Medinaceli - Desvinculación, 294-37 (traslado de 22 de enero de 1684, en 69 ff.). Véase ADM, Malagón, 11-56.

79 Véase ADM, Medinaceli - Desvinculación, 287-19. Se trata de un informe histórico de la casa de Malagón, hecho en Madrid el 6 de mayo de 1723 por Luis de Salazar, sobre las sucesiones en el mayorazgo familiar (transcrito en Campo Real 1997, 737-739).

80 ADM, Malagón, 11-59: Roma, 11 de junio de 1575. Previamente, al menos desde 1570, habían surgido problemas con el capellán mayor del hospital pues pretendía nombrar al administrador, a lo que se opuso la patrona (véase ADM, Malagón, 11-57); de ahí esta bula papal. Y por otra bula del mismo papa, de 12 de febrero de 1579 se autorizaba la creación de jueces conservadores para el hospital (Ibidem, 13-31). de Zúñiga Requesens, señor de Molins de Rey y de Martorell, truncándose el matrimonio al poco tiempo por muerte de este en 1577. Por ello, al año siguiente Guiomar casaba de nuevo con Juan Enríquez de Guzmán, hijo de los condes de Alba de Liste. ${ }^{81}$

Por su parte, la ínclita doña Luisa de la Cerda fallecía en Madrid el 30 de noviembre de 1596, enterrándose -como su marido e hijo mayor - en la cripta funeraria de los patronos del hospital, siendo con razón considerada por muchos el verdadero baluarte de la etapa de consolidación de la fundación hospitalaria de San Juan Bautista. Pocos años después, el 16 de febrero de 1599, recién entronizado Felipe III, el nuevo monarca concedía a Juan Enríquez de Guzmán - con nombre de Juan Pardo-, como esposo de Guiomar Pardo Tavera, el título de Marqueses de Malagón. ${ }^{82}$

La marquesa Guiomar suscribió, junto con el administrador del hospital (que no era otro que el propio biógrafo del cardenal Pedro de Salazar y Mendoza) nuevas constituciones para el régimen y gobierno del establecimiento, fechadas en Madrid el 28 de marzo de $1603,{ }^{83}$ y aún tuvo que hacer en ellas algunos retoques durante los dos años siguientes. ${ }^{84}$

Pero ninguno de los dos matrimonios ya reseñados de Guiomar, ni un tercero contraído en 1606 con el marqués de Frechilla, Duarte de Portugal, ${ }^{85}$ le dieron a la tercera patrona del hospital Tavera descendencia alguna, por lo que se extinguió con ella en 1622 la línea de los Arias PardoTavera, no sin antes haber tenido tiempo de contemplar no solo toda la fábrica del templo del hospital sino también la mayor parte de su ornamentación.

\section{Patronos de otros linajes: Ulloa-Sarmiento y Arias de Saavedra}

Tras la muerte de doña Guiomar y la resolución de una serie de pleitos, en cuyo tiempo el marquesado de Malagón estuvo vacante, el mayorazgo de la casa recayó en la persona de Diego de Ulloa Sarmiento ( ? -1647), II conde de Villalonso, como más propincuo varón y con mejor derecho a la sucesión por descender de una tía de la última titular de estos estados, también llamada Guiomar Pardo, que fue hermana de Arias Pardo de Saavedra y esposa de su bisabuelo, el tercer señor de Villalonso y Benafarces Juan de Ulloa Sarmiento. ${ }^{86}$

En su tiempo, concretamente en 1624, fue consagrada solemnemente la iglesia del hospital San Juan Bautista como reza en una de las inscripciones en lengua latina situada al lado de la epístola del templo.

Este marqués de Malagón del linaje Ulloa, cuarto patrono de la fundación hospitalaria, fallecía también sin descendencia en 1647, sucediéndole en los mayorazgos que había recibido su hermana Francisca de Ulloa Sarmiento, en

81 Sánchez González 2016: 211. Véase ADM, Medinaceli - Desvinculación, 287-19.

82 A.D.M., Archivo Histórico (Títulos), leg. 272-34 (antigua caja 2 n. 0 34-R).

83 ADM, Malagón, 11-71.

84 Ibídem, $12-5$ y 12-59.

85 Ibídem, 10-28: capítulos matrimoniales para este enlace (Madrid, 17 abril 1606).

86 Véase ADM, Medinaceli - Desvinculación, 287-19. 
TABLA 1

Genealogía de los patronos del hospital San Juan Bautista (Siglos XVI-XVIII)

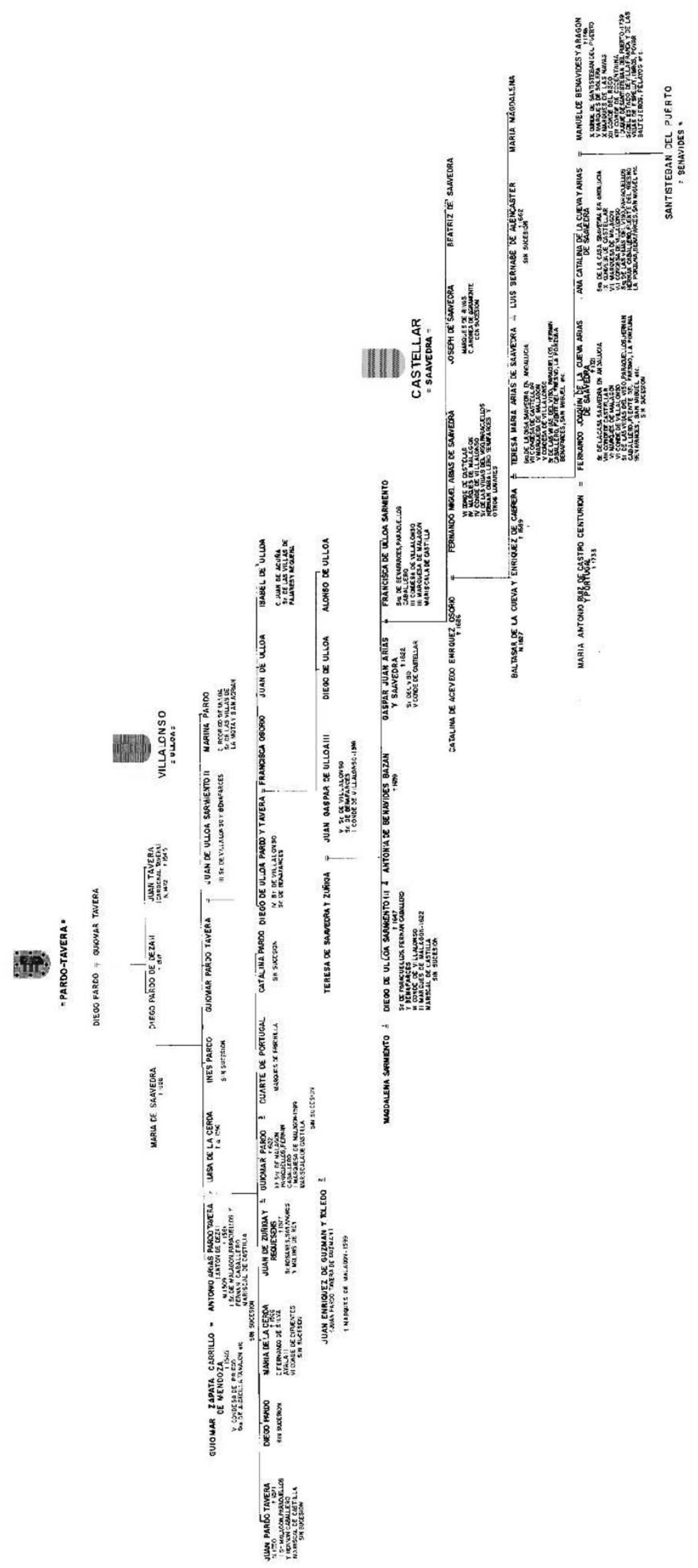


su condición de III marquesa de Malagón y III condesa de Villalonso, viuda por entonces del V conde del Castellar y señor de El Viso del Alcor Gaspar Juan Arias de Saavedra. De ahí que, poco después, en el primogénito del matrimonio, Fernando Miguel Arias de Saavedra y Ulloa Sarmiento ( ? - 1651), VI conde del Castellar, V marqués de Malagón y $\checkmark$ conde de Villalonso, mariscal y alfaqueque mayor de Castilla, y sexto patrono único del hospital San Juan Bautista, quedaran agregados todos esos estados patrimoniales, títulos y prebendas de los extintos Pardo-Tavera, junto con los de los Ulloa-Sarmiento, bajo la dirección de la casa andaluza de Castellar.

Fue también una sucesión efímera pues Fernando Miguel fallecía en 1651 y, a falta de descendencia masculina, le sucedía su hija mayor Teresa María Arias de Saavedra ( ? -1708), esposa desde 1664 de un hijo de los duques de Alburquerque llamado Baltasar de la Cueva y Enríquez de Cabrera, que llegó a ser ministro del Consejo de Órdenes y virrey del Perú. ${ }^{87}$

Posteriormente fue octavo patrono del hospital de Afuera el primogénito de ambos, Fernando Joaquín Arias de la Cueva Arias de Saavedra ( ? -1721), quien por su temprana muerte sin descendencia alguna, transmitió el patronazgo de la fundación San Juan Bautista a su hermana Ana Catalina de la Cueva Arias de Saavedra (1684-1735), desde 1721 titulada IX condesa del Castellar, VII marquesa de Malagón, condesa de Villalonso, etc.

\section{Patronazgo de los Santisteban-Malagón}

Previamente, desde 1707, dicha señora había contraído nupcias con el entonces heredero y, desde 1716, titular de la casa también andaluza de Santisteban del Puerto, Manuel de Benavides y Aragón (1682-1748), portador a su vez de un buen número de estados, títulos y dignidades pues había sucedido a su padre como X conde de Santisteban del Puerto (título que fue elevado a rango ducal en su persona el 20 de agosto de 1739 por privilegio del rey Felipe V, manifestando así el gran aprecio que le tenía el monarca) y como $\mathrm{V}$ marqués de Solera. ${ }^{88} \mathrm{E}$ incluso aún llegaría Manuel de Benavides a ensanchar más su ya dilatado patrimonio cuando en 1726 obtiene sentencia favorable de la chancillería de Granada en el pleito que tenía entablado con los marqueses de Aytona por la posesión del condado extremeño de Medellín.

Dicho patrimonio, paterno y materno, fue recibido por el primogénito del referido matrimonio, llamado Antonio de Benavides Arias de Saavedra (1714-1782), II duque de Santisteban del Puerto, VI marqués de Solera, XI de las Navas, VIII de Malagón y XIII de Medellín, XIV conde de Cocentaina, XIII del Risco, X del Castellar, VIII de Villalonso, etc. Siendo patrono del hospital, el arquitecto madrileño Pedro Martínez de Morales trazó en 1760 una nueva portada dedicada a San Juan Bautista, de tres cuerpos, para el frontispicio de la delantera, con pilastras y columnas de orden dórico en los dos pisos bajos y de orden jónico en el superior. La portada, de estilo barroco y poco acorde con el aire manierista de los prominentes sillares. Y aunque, en 1776, Pedro Arnal diseñó

87 Véase Sánchez González 2016, 212

88 ADM, Santisteban, 26-20: Toma de posesión de los estados (Madrid, 29 agosto 1716). cuatro soluciones distintas de portada neoclásica para sustituirla, este proyecto no se llevó a efecto.

Toda la descendencia de Antonio de Benavides en los tres matrimonios contraídos (con Ana Catalina de Toledo y Guzmán, María Pacheco Téllez-Girón y Ana María Fernández de Córdoba y Gonzaga, respectivamente) fue femenina, sucediéndole tras su muerte en 1782 la mayor de sus hijas, Joaquina María de Benavides y Pacheco (1746-1805) como titular de esta dilatada casa. ${ }^{89}$ Para entonces, y desde 1764, la flamante duquesa se hallaba desposada con el marqués de Cogolludo, Luis María Fernández de Córdoba y Gonzaga (1759-1806), ${ }^{90}$ como tal, heredero de toda la casa de Medinaceli, quien escasos años después, en 1789 , sucedió a su padre como XIII duque de Medinaceli y sus muchos títulos agregados.

\section{Patronazgo de los Medinaceli-Malagón}

Esta unión no solo propiciaba la consolidación de los Medinaceli como primera casa nobiliaria de España sino además la convertía también en la primera casa patrimonial de su tiempo. De ahí que, cuando ambos cónyuges fallecieron consecutivamente en los años iniciales del siglo XIX -ella en 1805 y él al año siguiente-, sucediera en este importantísimo patrimonio vinculado el primogénito del matrimonio integrador, Luis Joaquín Fernández de Córdoba y Benavides (1780-1840), llevando los títulos de XIV duque de Medinaceli y IV de Santisteban del Puerto, aparte de la larga nómina de agregados respectivos entre el que figuraba el de X marqués de Malagón. ${ }^{91}$ La casa de Medinaceli ejercería así, a partir de aquellos años, el patronato de la fundación San Juan Bautista en su calidad de portadora del título de marqués de Malagón. ${ }^{92}$

Esa centuria realmente significó una etapa agitada y decadente en la historia del hospital que se inició con la Guerra de la Independencia, durante la cual el administrador nombrado por el duque-patrono, el citado Luis Joaquín Fernández de Córdoba y Benavides (1805-1840), tuvo que defender denodadamente el inmueble de la rapiña del invasor francés pues el hospital de San Juan Bautista siempre fue un edificio muy codiciado por sus dimensiones y su magnificencia.

Posteriormente durante la desamortización, el hospital sufrió graves expolios al quedar desposeído de sus pingües rentas, en lo que fue un claro atropello a todo derecho. La tutela que le prestan sus patronos, los duques de Medinaceli-Marqueses de Malagón, es desautorizada injustamente por los principios revolucionarios al restar a las familias aristocráticas el prestigio que les posibilitaba a ejercer, en este caso con eficacia probada, sus muchas funciones benéficas. De esta forma, el capital dotacional del hospital San Juan Bautista quedó reducido a su mínima expresión, lo que no impidió que los referidos duques-patronos siguieran sos-

89 ADM, Santisteban, 26-27 a 31: Toma de posesión de los dominios de la casa de Santisteban y sus agregadas el 18 de abril de 1782 por parte de su marido, en nombre de ella.

90 ADM, Santisteban, 29-27: Capítulos matrimoniales para este enlace (Madrid, 1 febrero 1764).

91 Tomó posesión del patronato del hospital el 21 de febrero de 1805 (ADM, Malagón, 12-6).

92 Sánchez González 2016, 213. 
teniendo a un determinado número de enfermos. Por esa época, en la que ejercía el patronato de la fundación el XIV duque de Medinaceli Luis Tomás Fernández de Córdoba (1840-1873), quien firmó un contrato de cesión de parte del inmueble a los misioneros de la provincia del Rosario de Asia entre 1851 y 1859, y parece incluso que se pensó destinar el edificio como establecimiento militar. En octubre de 1860, por real orden del ministerio de la Guerra se declara transitoria la ocupación del hospital por los enfermos de cólera y se reconoce el derecho de patronato de los Medinaceli-Malagón sobre el establecimiento. ${ }^{93}$

Dentro de esa trayectoria decadente, a finales del mismo siglo XIX se perpetuó un importante robo en la iglesia del hospital, al parecer con la complicidad de los sacristanes, lo que propició que la duquesa viuda de Medinaceli y condesa de Ofalia Casilda de Salabert y Arteaga, como madre del duque-niño de Medinaceli Luis Jesús Fernández de Córdoba y Salabert (a quien, como marqués de Malagón, le correspondía entonces el patronato de San Juan Bautista), hizo llevar en 1887 a la congregación de las Hijas de la Caridad para que, además de atender a los ancianos y enfermos del hospital, velaran por el edificio. ${ }^{94} \mathrm{Al}$ mismo tiempo, las monjas iniciaban también la enseñanza a los niños pobres de los barrios circundantes del Arrabal y de Covachuelas, germen de las escuelas de San Juan Bautista. ${ }^{95}$

Entrado el siglo XX, en 1911 se trasladaban a la cripta familiar de los patronos, procedentes del cementerio de la iglesia de San Sebastián en Madrid, los restos mortales de algunos miembros de la Casa Ducal de Medinaceli, fallecidos durante las últimas décadas. Posteriormente la cripta subterránea del hospital era restaurada por acción conjunta del mencionado duque de Medinaceli Luis Jesús y de su tío carnal, el duque de Lerma Fernando María Fernández de Córdoba y Pérez de Barradas, ${ }^{96}$ encargando el primero los trabajos pertinentes de restauración al arquitecto madrileño Antonio Ferreras y Moya.

Con la guerra civil española, durante la cual el establecimiento funcionó como hospital de campaña, el edificio fue tomado por las milicias republicanas y tras la toma del Alcázar a fines de septiembre de 1936 las tropas franquistas ocuparon el hospital causando, uno y otro bando, graves destrozos en las obras de arte (entre ellos, la rotura de la nariz de la estatua yacente del sepulcro del cardenal Tavera). Nada más iniciarse la contienda fue asesinado en Madrid el citado duque de Lerma y este desgraciado suceso propiciaría la puesta en valor de una parte del edificio una vez acabado el conflicto armado.

A partir de entonces, el inmueble dejó de tener la función sanitaria que casi de forma ininterrumpida había venido prestando desde su origen, para conocer una profunda restauración historicista acorde con los nuevos fines a los que el viejo hospital quinientista iba a ser destinado en ade-

93 ADM, Malagón, 12-15.

94 En virtud de convenio suscrito en Madrid el 13 de julio de dicho año (ADM, Malagón, 30-26).

95 En la actualidad persiste el colegio, donde se imparten Educación Infantil, Primaria y ESO.

96 El XIV duque de Lerma, Fernando María de Constantinopla Fernández de Córdoba y Pérez de Barradas (1860-1936), era el tercer hijo del XV duque de Medinaceli Luis Tomás Fernández de Córdoba y Ponce de León, y de la I duquesa de Denia y Tarifa Ángela Pérez de Barradas y Bernuy. lante. Pues, al objeto de cumplir las mandas testamentarias de su difunto esposo, la duquesa viuda de Lerma María Luisa Bahía y Chacón, solicitó del referido duque de Medinaceli y patrono único del hospital la cesión de una parte del edificio toledano, en bajo arrendamiento de carácter simbólico - concretamente el cuadrante suroeste- al objeto de exponer la colección de cuadros correspondiente al lote heredado por el malogrado duque de Lerma de la magnífica e inmensa pinacoteca perteneciente a la Casa Ducal de Medinaceli. ${ }^{97}$ Ello llevó consigo una intervención, que corrió a cargo del arquitecto Eduardo Lagarde Aramburu. Así, se remodeló la cripta, se modificó la torreta meridional y la torre de la esquina sureste, se transformó el ventanaje del tercer piso de la fachada y se cambió la distribución interior para albergar a distintas instituciones privadas. ${ }^{98}$ La duquesa viuda de Lerma acondicionó, con tal fin, esa zona del edificio recreándola de un modo historicista con mobiliario, ajuar y obras de arte de los siglos XVI y XVII, ${ }^{99}$ como aún hoy se puede contemplar en el museo abierto al público.

Por su parte, el sector oriental del edificio fue cedido por el duque de Medinaceli Luis Jesús, tras la guerra civil, a Auxilio Social - centro más tarde dependiente del Instituto Nacional de Asistencia Social- para albergue. Este se desmanteló a mediados de los años setenta del pasado siglo $y$, a partir de entonces, esta zona del edificio toledano sufrió un progresivo proceso de decadencia por no tener un destino permanente, hecho que quedó solventado a fines del mismo siglo XX cuando, con la ayuda del Ministerio de Cultura, se acometió una profunda rehabilitación de esta ala del antiguo hospital entre los años 1981-1993, lo que permitió entre otras cosas que culminara este proyecto con la ubicación en este sector del edificio de la Sección Nobleza del Archivo Histórico Nacional. ${ }^{100}$ La fundación Casa Ducal de Medinaceli, a través principalmente de la gestión de su actual Presidente, no se limitó solo entonces a facilitar este proyecto sino que acometió entonces una ingente labor de rehabilitación de la mayor parte del edificio, que le ha dado al inmueble la imagen y el carácter que hoy presentan.

\section{CONCLUSIONES}

Más como hombre de Estado que de Iglesia, que también, don Juan Pardo Tavera adquirió un patrimonio en bienes y rentas que legó a su familia en un triple mayorazgo y varias donaciones inter vivos. Sabedor de que, con ello, su linaje quedaba garantizado, quiso el cardenal dejar como heredero universal de sus bienes libres a los más necesitados, a los que peor lo pasaban en aquella sociedad de mendigos y pícaros del Antiguo Régimen. De ahí la construcción del hospital de San Juan Bautista en Toledo, una de las obras

97 Ese lote, que en nuestros días puede seguir apreciando el visitante de este museo, representa casi una veinteava parte de lo que fue el conjunto de la colección pictórica de los Medinaceli, lo que da una idea de la importancia que ésta tuvo en su momento.

98 Marías 2007, 180

99 A tal efecto, María Luisa Bahía y Chacón, para perpetuar la memoria de su extinto marido, creó entre los años 1942-1943 la llamada fundación Duque de Lerma para becar a niñas necesitadas en el orfelinato que erigió en el antiguo hospital, niñas que también recibían enseñanza en el colegio de San Juan Bautista a cargo de las Hijas de la Caridad.

100 Actualmente denominado Archivo Histórico de la Nobleza. 
cumbres de la arquitectura del Renacimiento español y, desde luego, su mejor legado a la posteridad.

El edificio tiene una traza orgánica, sometida a proporciones y reglas numéricas, en una concepción claramente clasicista, desornamentada y basada en tipologías arquitectónicas antiguas revestidas de funciones modernas para la época. Por ello, el inmueble rompe radicalmente con la arquitectura anterior y supone el pleno entendimiento con la arquitectura renacentista italiana, materializando algunas de sus soluciones por primera vez en Castilla.

Mezcla de equilibrio y sobriedad, el gigantesco edificio nació como fundación de un hombre público con notable influencia en la esfera del poder en su tiempo. Por ello fue concebido en la clara estructura dual acorde con la doble finalidad de hospital general y capilla sepulcral de su fundador y de los sucesivos patronos de la institución.

Su importancia en la configuración espacial de Toledo determinará, entre otras razones, que cuando El Greco en 1610 pinte el lienzo de su Vista de Toledo presente en primer plano sobre una nube al hospital, distorsionando la realidad al colocarlo mirando al espectador en lugar de a la ciudad, lo que le convierte de esa manera en uno de sus símbolos más representativos. ${ }^{101} \mathrm{Y}$ es que por su situación real, el inmueble se enfrenta a la ciudad constituyendo el punto culminante del arrabal extramuros, tanto en altura como en presencia física. Su inmensa cúpula se hace visible desde lejos y sus amplias dimensiones, sobre una superficie total de $\mathbf{2 5 . 0 0 0}$ metros cuadrados, se perciben desde el valle y desde la propia ciudad.

\section{FIGURA 5}

Vista y plano de Toledo de El Greco, con el hospital Tavera en primer término, 1610

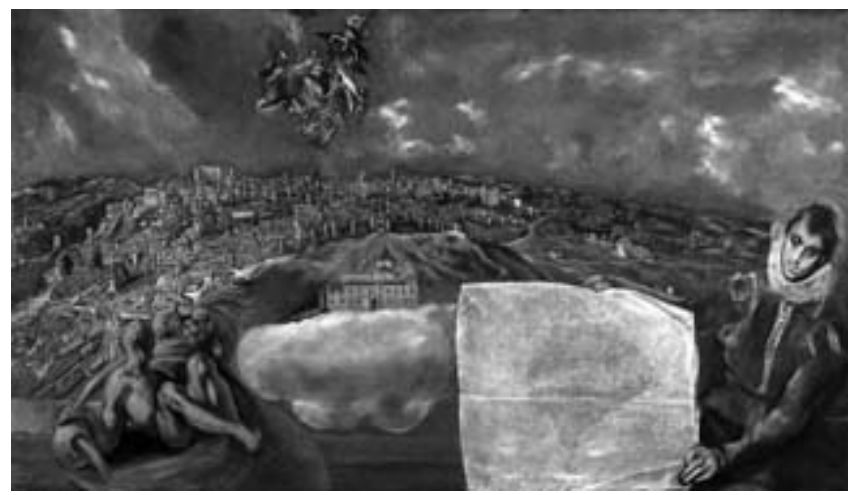

Fuente: Museo del Greco, CE00014.

El mecenazgo de don Juan Tavera expresaba así la nueva mentalidad social propia del Estado moderno y, sobre todo, su inmenso amor por los más desvalidos. Pese a ello, la suntuosidad del edificio (con un montante cercano a los 600.000 ducados en la construcción de su fábrica) testimoniaba que parecía mucho más que un establecimiento para enfermos y que, obviamente, se trataba de algo más que de un hospital. En realidad, era todo un universo renacentista

101 Algunos han denominado al artista, acertadamente, como el extranjero que supo retratar el alma de Toledo. que después repetiría Felipe II, a nivel de Estado, en El Escorial.

Precisamente el influyente cardenal toledano no dejó esta magna obra confiada a la Iglesia ni al Estado, sino como fundación custodiada por su propia familia, lo que hoy se nos antoja que no fue un desacierto si tenemos en cuenta el largo servicio asistencial del establecimiento durante casi cinco siglos, además del servicio cultural (como archivo y museo) y educativo (como colegio) que el antiguo hospital presta hoy a la sociedad.

\section{BiBLIOGRAFÍA}

Campo Real, Francisco del. 1997. Malagón: Un señorío en el Campo de Calatrava. Tesis doctoral. UNED.

Campo Real, Francisco del. 2000. «Venta de la encomienda calatrava de Malagón al Mariscal de Castilla don Antonio Ares Pardo de Saavedra». En Las órdenes militares en la península ibérica, coord. Ricardo Izquierdo Benito y Francisco Ruiz Gómez, vol. 2, 1795-1816. Cuenca: Universidad de Castilla-La Mancha.

Castán Lanaspa, Javier. 1993. "A propósito del testamento de cardenal Tavera». Boletín del Seminario de Estudios de Arte y Arqueología 59: 365-378. https://dialnet.unirioja.es/descarga/ articulo/2688749.pdf

Cotarelo y Valledor, Armando. 1902. Fray Diego de Deza: ensayo biográfico. Madrid: Imprenta de José Perales y Martínez. http://bibliotecadigital.jcyl.es/es/catalogo_imagenes/grupo. cmd?path $=10067267$

Díez del Corral Garnica, Rosario. 1987. Arquitectura y Mecenazgo. La imagen de Toledo en el Renacimiento. Madrid: Alianza Forma.

Fernández Collado, Ángel. 1999. La catedral de Toledo en el siglo XVI: vida, arte y personas. Toledo: Diputación Provincial de Toledo. https://books.google.es/books?id=9IL9x82k5U8C\&pg=PA242\&dq =juan+tavera\&hl=es\&sa=X\&ved=0ahUKEwj3ycjivMXiAhUa6OAKH XC1DEUQ6AEINTAD\#v=onepage \& $q=j u a n \% 20$ tavera\& $f=$ true

Fernández Duro, Cesáreo. 1891. Colección Bibliográfico-Biográfica de noticias referentes a Zamora y su provincia o Materiales para su Historia. Madrid: Imprenta y Fundición de Manuel Tello.

Franco Silva, Alfonso. 2001. "La desamortización de bienes de órdenes militares en la época de Carlos V: los casos de Paracuellos y Malagón». En Carlos V, europeísmo y universalidad: población, economía y sociedad, coord. Juan Luis Castellano y Francisco Sánchez-Montes, vol. IV, 237-274. Granada: Sociedad Estatal para la Conmemoración de los Centenarios de de Felipe II y Carlos V.

Gámez Martín, José. 2014. «Inquisición, mitra y carisma. Don Fray Diego de Deza, arzobispo de Sevilla. Brevísima aproximación a un hombre y su época». En Inquisición. Actas de las XIV Jornadas de Historia en Llerena, coord. Felipe Lorenzana de la Puente y Francisco J. Mateos Ascacíbar, 163-176. Llerena: Sociedad Extremeña de Historia.

Gómez Moreno, Manuel. 1983. Las águilas del renacimiento español: Bartolomé Ordóñez, Diego Siloé, Pedro Machuca, Alonso Berruguete: 1571-1588. Madrid: Xarait.

Hermoso Armada, Adriana. 1988. La farmacia del hospital Tavera. Tesis doctoral. Universidad de Granada.

Mann, Richard G. 1984. "Los retablos para el Hospital de San Juan Bautista de Afuera (Toledo)». En Visiones del pensamiento: El Greco como intérprete de la historia, la tradición y las ideas, Jonathan Brow, 93-124. Madrid: Alianza.

Marías Franco, Fernando. 2007. El Hospital Tavera de Toledo. [Sevilla]: Fundación Casa Ducal de Medinaceli.

Marqués de Lozoya, Juan de Contreras y López de Ayala. 1967. Historia de España. Tomo IV. Madrid: Salvat.

Martínez-Burgos García, Palma. 1997. «Origen de la teoría artística de la contrarreforma: el cardenal Tavera y el Concilio provincial de Toledo de 1536». En Ensayos humanísticos: homenaje al profesor Luis Lorente, 285-302. Toledo: Universidad de Castilla-La Mancha.

Olivera Serrano, Cesar. 1999. "La Galicia de Vasco de Aponte: los pleitos del arzobispo Tabera contra los linajes de la Tierra de Santiago». En la España medieval 22: 285-316. 
Paz y Remolar, Ramón. 1978. «El Cardenal Tavera, asesor político de Carlos V». En Estudios Genealógicos, Heráldicos y Nobiliarios en honor de Vicente de Cadenas y Vicent, 123-127. Madrid: Hidalguía. https://books.google.es/books?id=utOmTtZlzt8C\&pg=PA1 $26 \& d q=$ cardenal+tavera $\&$ hl=es $\&$ sa $=X \& v e d=0$ ahUKEwiLgqWFvM XiAhUHA2MBHTJHDUgQ6AEILjAB\#v=onepage \&q=cardenal\%20 tavera\&f=true

Rodríguez Gutiérrez de Ceballos, Alfonso. 1967. Bartolomé de Bustamante y los orígenes de la Arquitectura Jesuítica en España. Roma: Institutum Historicum Societatis lesu.

Rumeu de Armas, Antonio. 2006. «El Cardenal Tavera, Gobernador General de España». Boletín de la Real Academia de la Historia CCIII, II: 163-188. https://books.google.es/books?id=|B9dGAEGUd8C\& pg=PA163\&dq=cardenal+tavera\&hl=es\&sa=X\&ved=0ahUKEwiLgq WFvMXiAhUHA2MBHTJHDUgQ6AEISTAG\#v=onepage\& $q=$ carden al\%20tavera\&f=false

Salazar y Mendoza, P. de. 1603. Chronico de el Cardenal Don luan Tauera, arzobispo de Toledo. Toledo: Pedro Rodríguez Impresor. http:// bdh-rd.bne.es/viewer.vm?id=0000115040\&page $=1$
Sánchez González, Antonio. 2015. El Archivo de los Caudillos del reino de Jaén (Casa de Santisteban del Puerto). Jaén: Instituto de Estudios Giennenses.

Sánchez González, Antonio. 2016. «Heráldica episcopal hispana: la capilla de San Pedro de la Catedral de Sevilla y sus vestigios emblemáticos». Tabularium Edit 3: 198-224.

Sánchez González, Antonio. 2017. «Nobleza, archivo y mayorazgo». En Escritura y sociedad: la nobleza 329-342, coord. Ana Suárez González. Santiago de Compostela: Universidad de Santiago de Compostela.

Sánchez González, Antonio. 2021. «Los Archivos del Cardenal: el fondo documental sevillano de D. Juan Pardo Tavera». Studia Historica. Historia Moderna 43 (1): 229-257. https://doi.org/10.14201/ shhmo2021431229257

Zamorano Rodríguez, María Luisa. 2002. Historia del Hospital de San Juan Bautista de Toledo durante el siglo XVI. Tesis doctoral. Universidad Complutense de Madrid. http://eprints.ucm.es/ tesis/19911996/D/0/AD0029801.pdf 